Superalloys 2012: 12 ${ }^{\text {th }}$ International Symposium on Superalloys

\title{
EFFECT OF THERMAL CYCLING ON HIGH TEMPERATURE CREEP OF COATED CMSX-4
}

\author{
Raphaël Goti ${ }^{1,2}$, Bernard Viguier ${ }^{2}$, Fabrice Crabos ${ }^{1}$ \\ ${ }^{1}$ TURBOMECA-SAFRAN group, Avenue Joseph Szydlowski 64511 Bordes Cedex, France \\ ${ }^{2}$ Université de Toulouse, Institut Carnot CIRIMAT, INP/ENSIACET, 4 allée Emile Monso, 31030 Toulouse, France
}

Keywords: High temperature creep, Thermal cycling, Coating/superalloy system

\begin{abstract}
Effect of thermal cycling on high temperature creep of thin-walled and coated CMSX-4 single crystal superalloy was evaluated by performing thermal cycling and isothermal creep tests at $1050^{\circ} \mathrm{C}$ and $140 \mathrm{MPa}, 1150^{\circ} \mathrm{C}$ and $140 \mathrm{MPa}$ and $1150^{\circ} \mathrm{C}$ and $80 \mathrm{MPa}$. The deleterious effect of thermal cycling on the creep behavior and lifetime has been confirmed, particularly for the condition at $1150^{\circ} \mathrm{C}$ and $80 \mathrm{MPa}$. Furthermore, the number of low temperature incursions has severe detrimental effect on creep resistance on account of the rafted microstructure destabilization induced by these sequences. These results confirm the role of re-precipitation and dissolution of $\gamma^{\prime}$ particles during thermal cycling creep. Thermal cycling infers also on destabilization of subcoating zone in the superalloy but this effect seems to be secondary.
\end{abstract}

\section{Introduction}

Creep behavior of single crystal nickel-based superalloys at constant stress and constant temperature has been extensively studied for the last decades [1-4]. However these superalloys are used for the fabrication of high-pressure turbine blades that are subjected to complex very high temperature loadings $\left(\mathrm{T}>1000^{\circ} \mathrm{C}\right)$. Few works have been realized to analyze the effect of temperature variations on creep properties and it has been shown that creep under non-isothermal conditions strongly affects the creep resistance of superalloys [5-14]. Moreover, in order to improve their resistance to high temperature corrosion and oxidation, a protective NiCoCrAlYTa coating is deposited on the surface of the uncooled HP blades [15]. In order to optimize both the cooling efficiency and the weight of fast rotating turbine blades a general trend is to reduce the wall thickness of the hollow investment casting parts. It has been shown that reducing the wall thickness leaded to lower lifetimes and higher minimum creep rates [16-18]. Besides in the case of thin-coated specimens it could be explained at least partly by the reduction of the load bearing because of the interdiffusion between coating and superalloy [18]. The purpose of this paper is to study the influence of thermal cycling on high temperature creep of thin-walled and coated CMSX-4 single crystal superalloy. Therefore creep tests are performed at three conditions at very high temperature $\left(1050^{\circ} \mathrm{C}\right.$ and $\left.1150^{\circ} \mathrm{C}\right)$ to compare isothermal and thermal cycling creep behavior. A special attention will be paid to the evolution and stability of the $\gamma / \gamma$ ' rafted microstructure, the evolution of microstructure in the interdiffusion zone between coating and superalloy as well as creep cavitation in the superalloy after rupture.

\section{Experimental procedure}

\section{Material and creep specimen preparation}

The material investigated here is the single crystal nickel-based superalloy CMSX-4. This alloy is a second-generation superalloy developed by Cannon Muskegon, Muskegon, USA for gas turbine applications [19]. Its chemical composition is given in Table I.

Table I. Nominal composition of the CMSX-4 single crystal superalloy used in this study (in wt.\%)

\begin{tabular}{llllllllll}
\hline $\mathrm{Ni}$ & $\mathrm{Al}$ & $\mathrm{Co}$ & $\mathrm{Cr}$ & $\mathrm{Hf}$ & $\mathrm{Mo}$ & $\mathrm{Re}$ & $\mathrm{Ta}$ & $\mathrm{Ti}$ & $\mathrm{W}$ \\
$\mathrm{Bal}$ & 5.6 & 9.6 & 6.4 & 0.1 & 0.6 & 3.0 & 6.5 & 1.0 & 6.4 \\
\hline
\end{tabular}

The single crystal bars were solidified in the [001] direction (misorientation $<5^{\circ}$ ) and solution-treated by Doncasters Precision Castings, Bochum, Germany. Flat thin-wall ( $0.8 \mathrm{~mm}$ thick) creep specimens were spark machined from CMSX-4 bars and the sample surface parallel to (100) plane. Gauge part of the sample was $29 \mathrm{~mm}$ in length and $4 \mathrm{~mm}$ in width. Creep specimens were then coated with a $70 \mu \mathrm{m}$ thick electrolytic NiCoCrAlYTa deposit. The coating was provided by Praxair Surface Technologies, Oldmixon Crescent, England, and made by the Tribomet $^{\mathrm{TM}}$ process, where CrAlY particles are entrapped in a growing Ni-Co electroplate layer to produce a uniform dispersion [20]. The nominal composition of NiCoCrAlYTa coating is given in Table II. MCrAlY coatings show significant improvements over aluminide coatings, especially a superior ductility [21]. By consequence in the tested conditions spallation of coating is negligible.

\begin{tabular}{cccccc}
\multicolumn{6}{c}{ Table II. Composition of NiCoCrAlYTa coating (in wt.\%) } \\
\hline $\mathrm{Ni}$ & $\mathrm{Co}$ & $\mathrm{Cr}$ & $\mathrm{Al}$ & $\mathrm{Y}$ & $\mathrm{Ta}$ \\
$\mathrm{Bal}$. & 23 & 20 & 8.5 & 0.6 & 4.5 \\
\hline
\end{tabular}

The full heat-treatment consisted of a two-step diffusion and ageing treatment, $4 \mathrm{~h}$ at $1100^{\circ} \mathrm{C}$ and $20 \mathrm{~h}$ at $870^{\circ} \mathrm{C}$ in argon atmosphere.

\section{$\underline{\text { Creep tests }}$}

Tensile creep tests under constant load were carried out up to rupture under air at temperatures of $1050^{\circ} \mathrm{C}$ and $1150^{\circ} \mathrm{C}$. A constant load was imposed during the total creep duration corresponding to the initial stress 80 or $140 \mathrm{MPa}$. Stress was determined by the net-cross section of the sample without coating. The specimens were heated in a radiation furnace. The expansion of the specimens was continuously measured by a laser beam going through the furnace giving an accuracy of $2 \mu \mathrm{m}$ at $1150^{\circ} \mathrm{C}$. In order to study the influence of thermal cycling on the creep properties and to compare it with isothermal creep tests, thermal cycles were imposed with a high temperature dwell time set to either 5 minutes or 1 hour depending on the creep test temperature. Such cycles are corresponding to temperature change rates used in a previous study [13].

Three conditions were studied in this paper and two tensile creep tests were performed for each condition, one thermal cycling and one isothermal creep tests. For the first condition, thermal cycling and isothermal creep tests were performed at the high temperature level of $1050^{\circ} \mathrm{C}$ and under the constant load of $140 \mathrm{MPa}$, with a 
high temperature dwell time set to 1 hour during the thermal cycling creep test. The high temperature dwell was followed by a low temperature incursion which was set to be 10 minutes long: 5 minutes cooling down to $0^{\circ} \mathrm{C}$ then 5 minutes heating, back to $1050^{\circ} \mathrm{C}$ using three successive heating rates $\left(6^{\circ} \mathrm{C} \cdot \mathrm{s}^{-1}\right.$ up to $900^{\circ} \mathrm{C}$, $2^{\circ} \mathrm{C} . \mathrm{s}^{-1}$ from 900 to $1000^{\circ} \mathrm{C}$ and finally $0.5^{\circ} \mathrm{C} . \mathrm{s}^{-1}$ to $1050^{\circ} \mathrm{C}$ ) in order to avoid any overheating when reaching the next $1050^{\circ} \mathrm{C}$ dwell. However the thermal inertia of the load train does not allow such a temperature profile and the actual cooling rate decreases rapidly which limits the lower temperature $\left(\right.$ about $350^{\circ} \mathrm{C}$ ).

For the second condition, thermal cycling and isothermal creep tests were realized at the temperature of $1150^{\circ} \mathrm{C}$ and under the constant load of $140 \mathrm{MPa}$. During the thermal cycles of thermal cycling creep test, a 5 minutes high temperature dwell time was imposed. The low temperature incursion was also set to be 10 minutes long with 5 minutes cooling down to $0^{\circ} \mathrm{C}$ then 5 minutes heating, back to $1050^{\circ} \mathrm{C}$. Only the first heating rate was much higher in comparison with the heating rates of the first condition at $1050^{\circ} \mathrm{C}$ : $6.7^{\circ} \mathrm{C} \cdot \mathrm{s}^{-1}$ up to $1000^{\circ} \mathrm{C}$ for the second condition at $1150^{\circ} \mathrm{C}$.

Finally the third condition was similar to the second one with the same high temperature level $\left(1150^{\circ} \mathrm{C}\right)$ and identical thermal cycles but with a much lower constant load of $80 \mathrm{MPa}$. The specimen temperature, recorded during the thermal cycle used for the second and third conditions is represented in Figure 1.

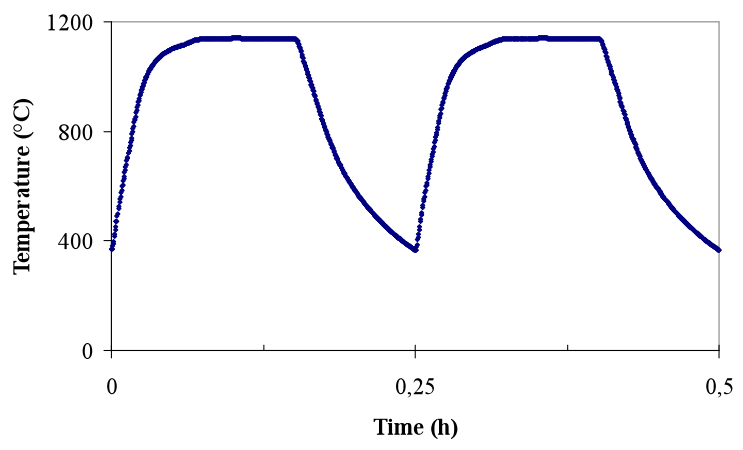

Figure 1 . Thermal cycle used during creep tests at $1150^{\circ} \mathrm{C}$

\section{Observations}

After rupture, creep test specimens were examined by scanning electron microscopy (SEM) with X-ray energy dispersive spectroscopy (XEDS). The observed creep test specimens were not necessary the same ones for the three conditions that those presented in the creep test results paragraph. The secondary electron mode was used on gauge sections parallel to the stress axis of the creep specimens. After mechanical polishing, the $\gamma$ phase was etched electrolytically ( $4 \mathrm{~V}$ d.c.) using a mixture of 13 $\mathrm{ml}$ phosphoric, $45 \mathrm{ml}$ sulphuric and $42 \mathrm{ml}$ nitric acids. The $\gamma$ phase appears in dark on all the SEM micrographs.

Attention has been firstly paid to the observation of the $\gamma / \gamma$ ' microstructure on specimen cross-sections taken $10 \mathrm{~mm}$ away from the rupture area. The evolution of microstructure in the interdiffusion zone between coating and superalloy has then been studied as well as creep cavitation in the superalloy after rupture.

\section{Results}

\section{Creep test results}

Thermal cycling tests have been compared with isothermal creep tests for each condition. The normalized strain (strain / rupture strain of the isothermal test) has been plotted as a function of time/lifetime of the isothermal creep test for the three conditions. Following the work by Raffaitin et al. [5] we supposed that creep deformation occurred only during the high temperature dwells. In consequence the thermal cycling creep curves have been rebuilt by keeping only the part of the curves corresponding to the time spent at high temperature level. In Figure 2.a), b) and c) are represented the curves of thermal cycling (TC) and isothermal (I) creep tests for the conditions $1050^{\circ} \mathrm{C}-140 \mathrm{MPa}, 1150^{\circ} \mathrm{C}-140 \mathrm{MPa}$ and $1150^{\circ} \mathrm{C}-80 \mathrm{MPa}$ respectively. In Figure 2.d) the strain / rupture strain of the test is plotted as a function of time / lifetime of the test for both creep tests, thermal cycling and isothermal, at $1150^{\circ} \mathrm{C}$ and under $80 \mathrm{MPa}$. This representation is used to compare the creep behavior of superalloy between thermal cycling and isothermal creep tests. The minimum creep rates $\dot{\varepsilon}$ were calculated from the curves shown in Figure 2.a), b) and c), that are with respect to high temperature time.

In Figure 2.a) for the condition $1050^{\circ} \mathrm{C}$ and $140 \mathrm{MPa}$, results show an increase $\left(1.89 * 10^{-4} \mathrm{~h}^{-1}\right.$ vs $\left.0.84 * 10^{-4} \mathrm{~h}^{-1}\right)$ of the minimum creep rate $\varepsilon$ for the thermal cycling creep test compared with the isothermal creep test. Moreover the cumulated high temperature rupture time of sample TC is 1.3 times lower than the lifetime of the sample I. During the thermal cycling creep test at $1050^{\circ} \mathrm{C}$ and $140 \mathrm{MPa}$, more than 200 cycles were imposed.

At $1150^{\circ} \mathrm{C}$ and $140 \mathrm{MPa}$ in Figure 2.b), similar conclusions can be drawn. Indeed in Figure 2.b) one can notice that thermal cycling decreases the total high temperature lifetime and increases the creep rate. For such high temperature and stress level the creep life is very short and the reduction of creep life due to thermal cycling is quite limited as for the previous condition. Indeed the high temperature lifetime of sample TC is shorter by $30 \%$ in comparison with sample I and the minimum creep rate $\dot{\varepsilon}$ of thermal cycling creep test is also higher $\left(1.84 * 10^{-2} \mathrm{~h}^{-1}\right.$ vs $1.10 *$ $\left.10^{-2} \mathrm{~h}^{-1}\right)$. Few tens of thermal cycles were imposed during the thermal cycling creep test at $1150^{\circ} \mathrm{C}$ and $140 \mathrm{MPa}$.

For the third condition at $1150^{\circ} \mathrm{C}$ and $80 \mathrm{MPa}$, thermal cycling very significantly affects the creep behavior of CMSX-4 superalloy as shown in Figure 2.c). Indeed thermal cycling severely increases the minimum creep rate $\dot{\varepsilon}\left(20 * 10^{-4} \mathrm{~h}^{-1}\right.$ vs $0.3 *$ $10^{-4} \mathrm{~h}^{-1}$ for sample I) and the cumulated high temperature rupture time is 6 times lower than the lifetime of sample I. During the thermal cycling creep test at $1150^{\circ} \mathrm{C}$ and $80 \mathrm{MPa}, 234$ cycles were imposed. The graph in Figure 2.d) allows to compare the shape of the creep curves, thus the creep behavior and damage, obtained under these conditions during isothermal and thermal cycling tests. The resolved curve corresponding to isothermal creep test exhibits a classical shape of alloy type creep curve, with very defined primary, secondary (minimum constant rate) and tertiary stages. The transition between secondary and tertiary stages is quite abrupt and the strain recorded during tertiary stage is low, indicating that damaging process may start quite late and be localized. Conversely the thermal cycling creep test curve is much more rounded with a very limited secondary stage and a smooth transition to the tertiary stage that accounts for a very large strain. 

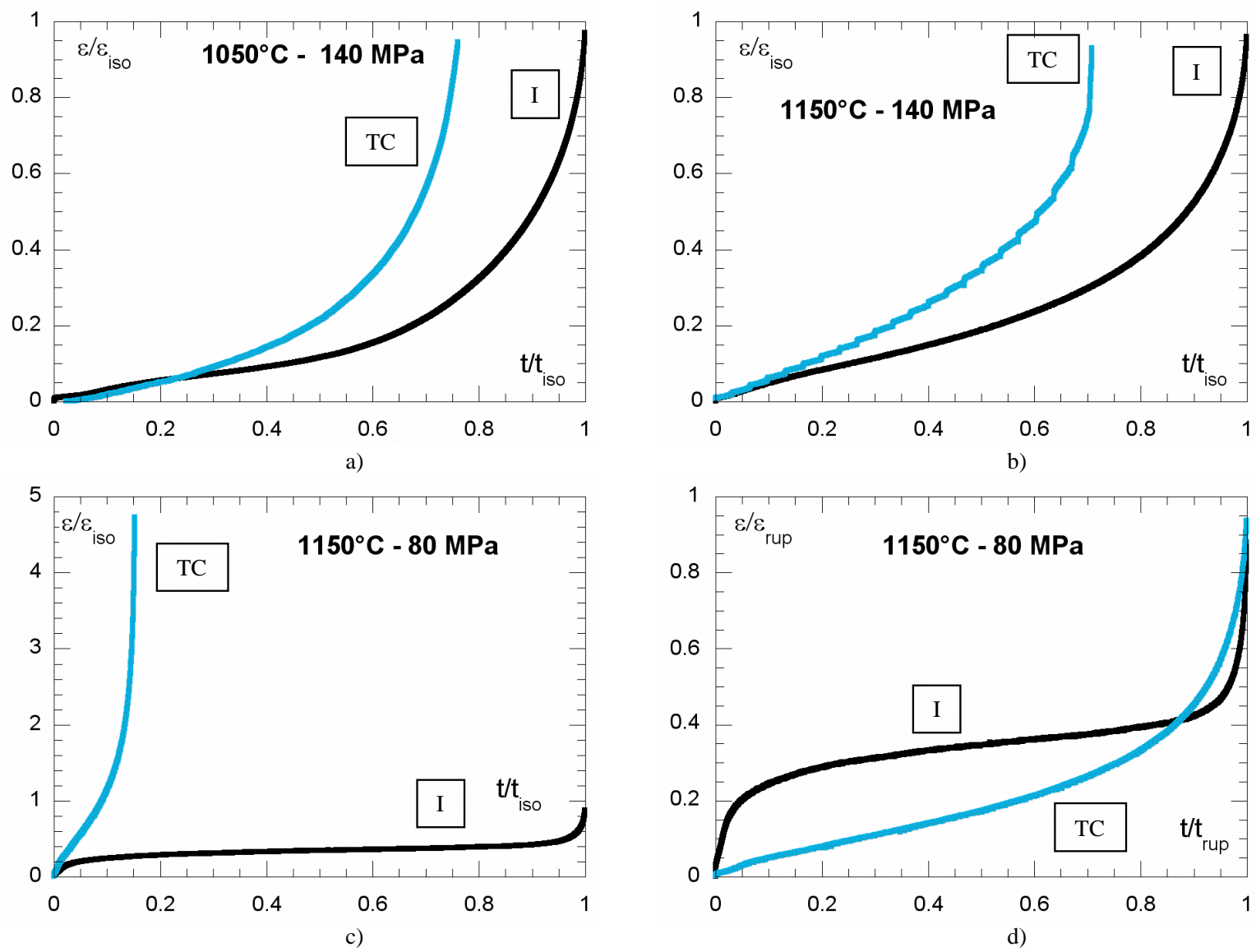

Figure 2. a), b), c) High temperature normalized strain during thermal cycling (TC) and isothermal (I) creep tests achieved at $1050^{\circ} \mathrm{C}$ $140 \mathrm{MPa}, 1150^{\circ} \mathrm{C}-140 \mathrm{MPa}$ and $1150^{\circ} \mathrm{C}-80 \mathrm{MPa}$ respectively; d) strain / rupture strain during thermal cycling (TC) and isothermal (I) creep tests achieved at $1150^{\circ} \mathrm{C}-80 \mathrm{MPa}$.

This evolution of the rupture strain and of the shape of the creep curve is most probably related to a modification of the damaging processes in the superalloy during thermal cycling creep, suggesting that in this case the damaging should start earlier and be more evenly distributed.

The present results confirm the finding that imposing thermal cycles during a creep experiment alters significantly creep resistance of $\gamma / \gamma^{\prime}$ single crystal superalloys $[5,13]$. It must be emphasized that this detrimental effect is all the more severe at very high temperatures and with a large number of thermal cycles.

\section{$\gamma / \gamma^{\prime}$ microstructure observations}

Microstructural observations have been performed by scanning electron microscopy on crept specimens under the various conditions previously presented (the micrographs shown hereafter do not necessarily correspond to the same specimens than the creep curves in Figure 2). Observations have been realized on specimen longitudinal cross-sections taken $10 \mathrm{~mm}$ away from the rupture area and are reported in Figure 3 for the six specimens. The horizontal direction corresponds to the load axis and the vertical one to the specimen thickness. For all the cases, the superalloy exhibits a $\gamma^{\prime}$ rafted precipitates configuration.
In Figure 3.a), b), c) and d) measurements by the image analysis Visilog ${ }^{\circledR}$ showed that $\gamma^{\prime}$ rafts thicknesses and $\gamma$ corridors widths were quite similar in the specimens crept under isothermal and cyclic conditions. For both conditions at $1050^{\circ} \mathrm{C}-140 \mathrm{MPa}$ and $1150^{\circ} \mathrm{C}-140 \mathrm{MPa}$ thermal cycling seems thus to have little effect on the rafted microstructure. On the other hand for the third condition at $1150^{\circ} \mathrm{C}$ and $80 \mathrm{MPa}$ (Figure 3.e) and f)) it was clearly visible by comparing thermal cycling and isothermal creep samples that the microstructure was coarser in the specimen crept under cyclic conditions (both $\gamma^{\prime}$ rafts and $\gamma$ corridors was thicker). Moreover one can also notice that after thermal cycling creep, raft edge and in some case the whole raft itself start to rotate away from the $\mathrm{N}$ orientation, principally at $1150^{\circ} \mathrm{C}$ and $80 \mathrm{MPa}$. Such reorientation of the rafts has been proven to be associated to a local damage of the superalloy [7,22].

According to a procedure previously established by Fredholm [23] and used by Caron et al. [24], image analysis software Visilog ${ }^{\circledR}$ allowed to measure the specific connectivity number of the $\gamma$ ' phase $\mathrm{N}_{\mathrm{A}}\left(\gamma^{\prime}\right)$. It is defined as the number of particles of this phase less the number of holes contained within these particles, per area unit [25]. To quantify the $\gamma^{\prime}$ phase connectivity the $\gamma^{\prime}$ phase was skeletised and $\mathrm{N}_{\mathrm{A}}\left(\gamma^{\prime}\right)$ was calculated using the following expression: 


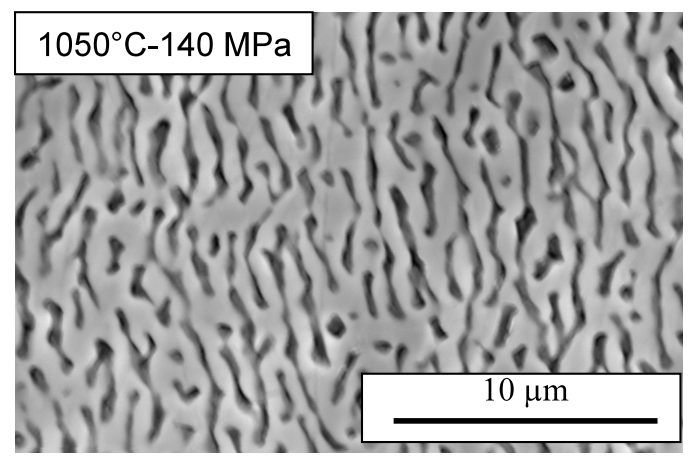

a)

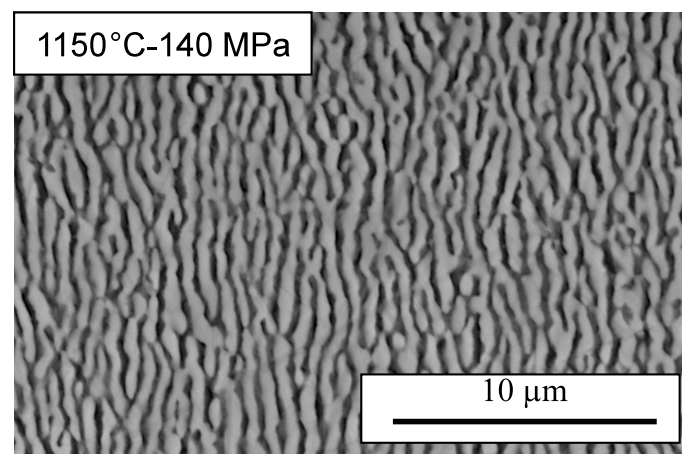

c)

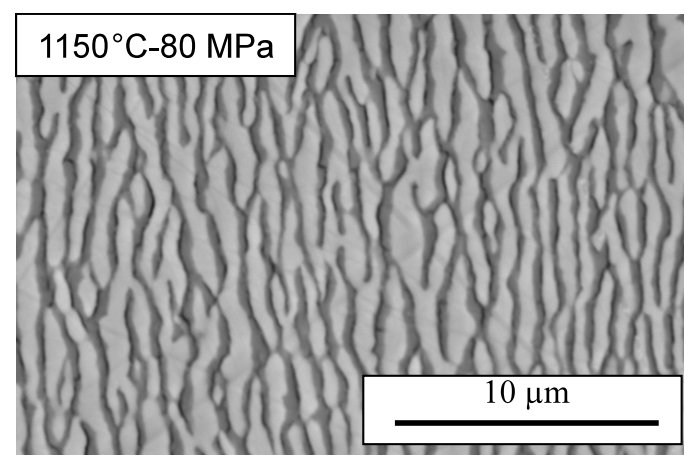

e)

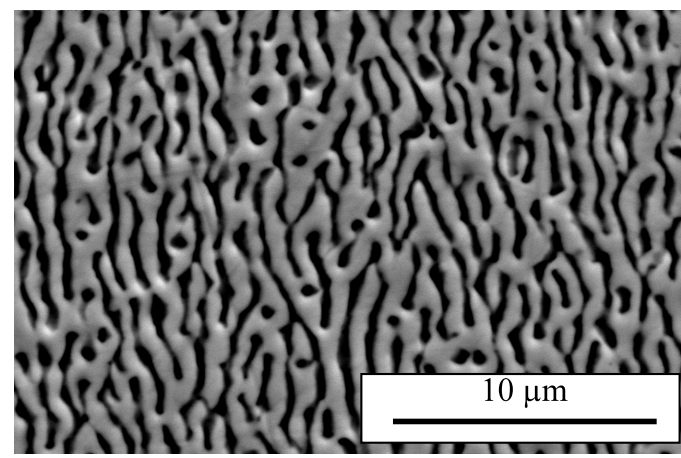

b)

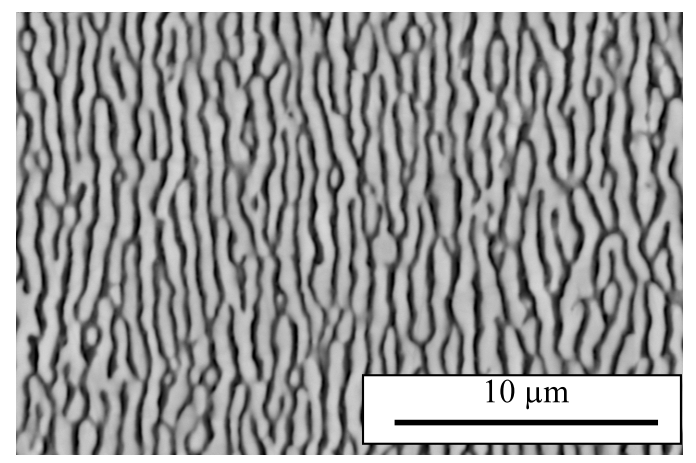

d)

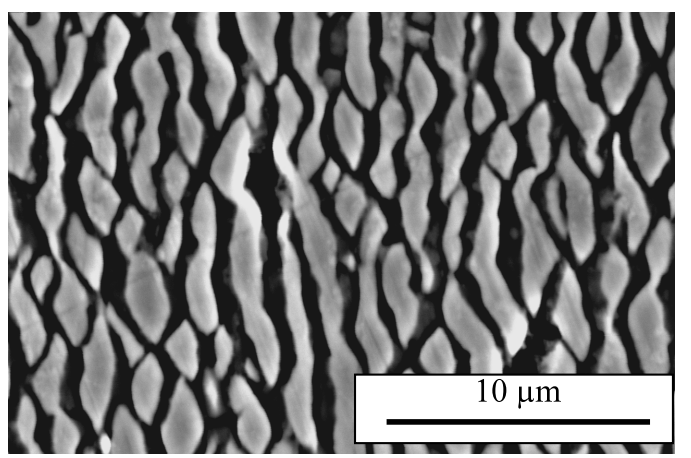

f)

Figure 3. SEM micrographs of cross-sections of CMSX-4 samples after creep tests at $1050^{\circ} \mathrm{C}-140 \mathrm{MPa}$ (a) and b)); $1150^{\circ} \mathrm{C}-140 \mathrm{MPa}(\mathrm{c})$ and d)) and $1150^{\circ} \mathrm{C}-80 \mathrm{MPa}(\mathrm{e})$ and f)). Column to the left: isothermal; column to the right: thermal cycling conditions.

$\mathrm{N}_{\mathrm{A}}\left(\gamma^{\prime}\right)=\left(\mathrm{N}_{\mathrm{T}}-\mathrm{N}_{\mathrm{TP}}\right) / 2 \mathrm{~S}$

where $\mathrm{N}_{\mathrm{T}}$ is the termination number and $\mathrm{N}_{\mathrm{TP}}$ the triple point number of the $\gamma^{\prime}$ skeleton, and $\mathrm{S}$ is the area of the analyzed field. Topological inversion occurs when $\mathrm{N}_{\mathrm{A}}\left(\gamma^{\prime}\right)$ becomes negative. In our study, for both conditions at $1150^{\circ} \mathrm{C}$ (Figure 3.c), d), e), f)), $\mathrm{N}_{\mathrm{A}}\left(\gamma^{\prime}\right)$ remains positive that means that the $\gamma^{\prime}$ phase particles are always surrounded by the matrix at $1150^{\circ} \mathrm{C}$. By contrast, measurements on Figure 3.a) and b) highlighted a $\gamma / \gamma^{\prime}$ topological inversion since $\mathrm{N}_{\mathrm{A}}\left(\gamma^{\prime}\right)$ is negative after thermal cycling and isothermal creep tests at $1050^{\circ} \mathrm{C}$ and $140 \mathrm{MPa}$. $\gamma$ ' phase area fraction has not been measured very precisely but fractions were similar between isothermal and thermal cycling tests for each condition
Interdiffusion zone observations

The microstructure of the NiCoCrAlYTa coating [26-28] consists initially of $\beta-\mathrm{NiAl}$ and $\gamma^{\prime}-(\mathrm{Ni}, \mathrm{Cr})_{3} \mathrm{Al}$ islands in a $\gamma$-Ni matrix. As the NiCoCrAlYTa oxidizes, grains of the aluminium-rich $\beta$ phase gradually convert to islands of $\gamma^{\prime}$ by consumption of the aluminium to form the oxide scale. Dissolution of the $\beta$ phase near the coating/alloy interface is also observed due to the interdiffusion with the substrate. These interdiffusion phenomena can alter the microstructure and composition of the subcoating region of the substrate and therefore may affect the mechanical properties of the protected components. 


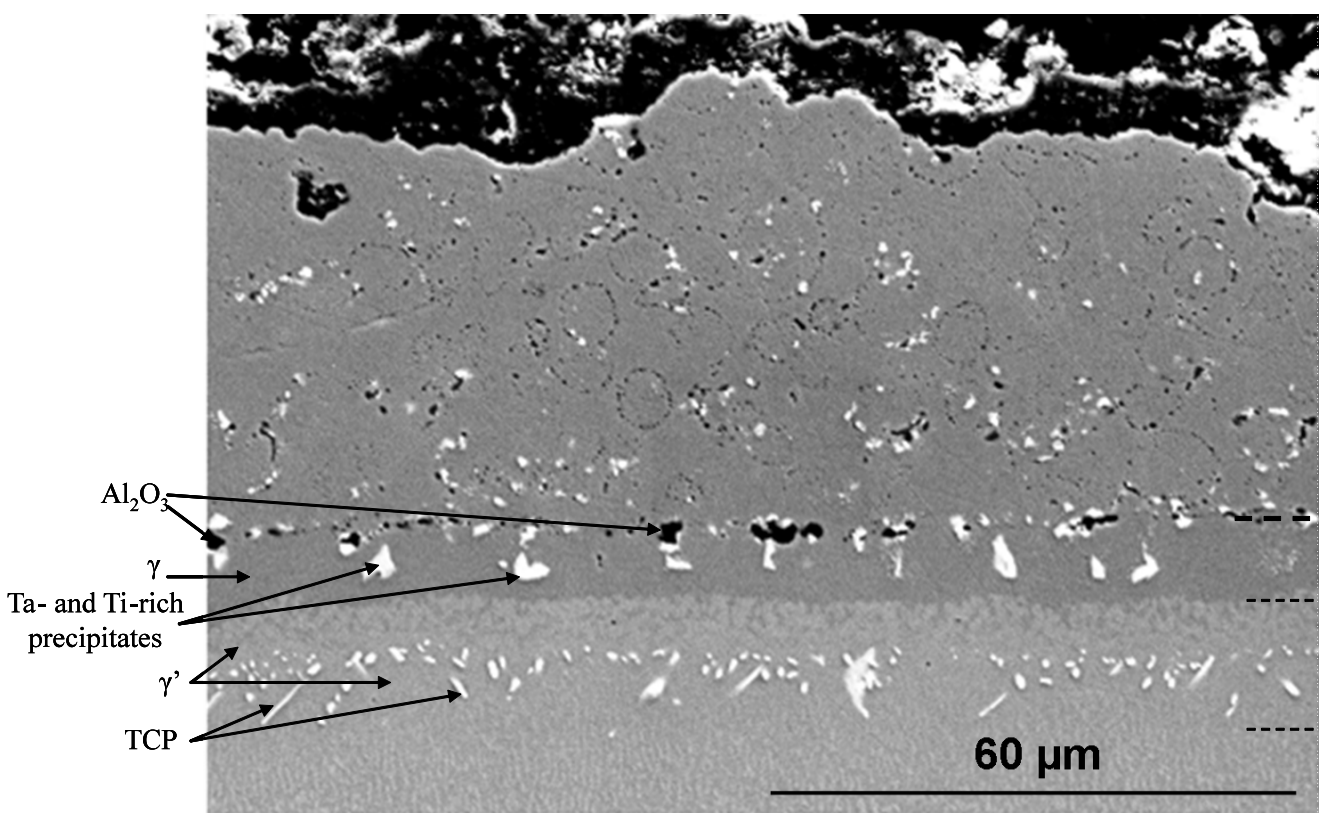

a)

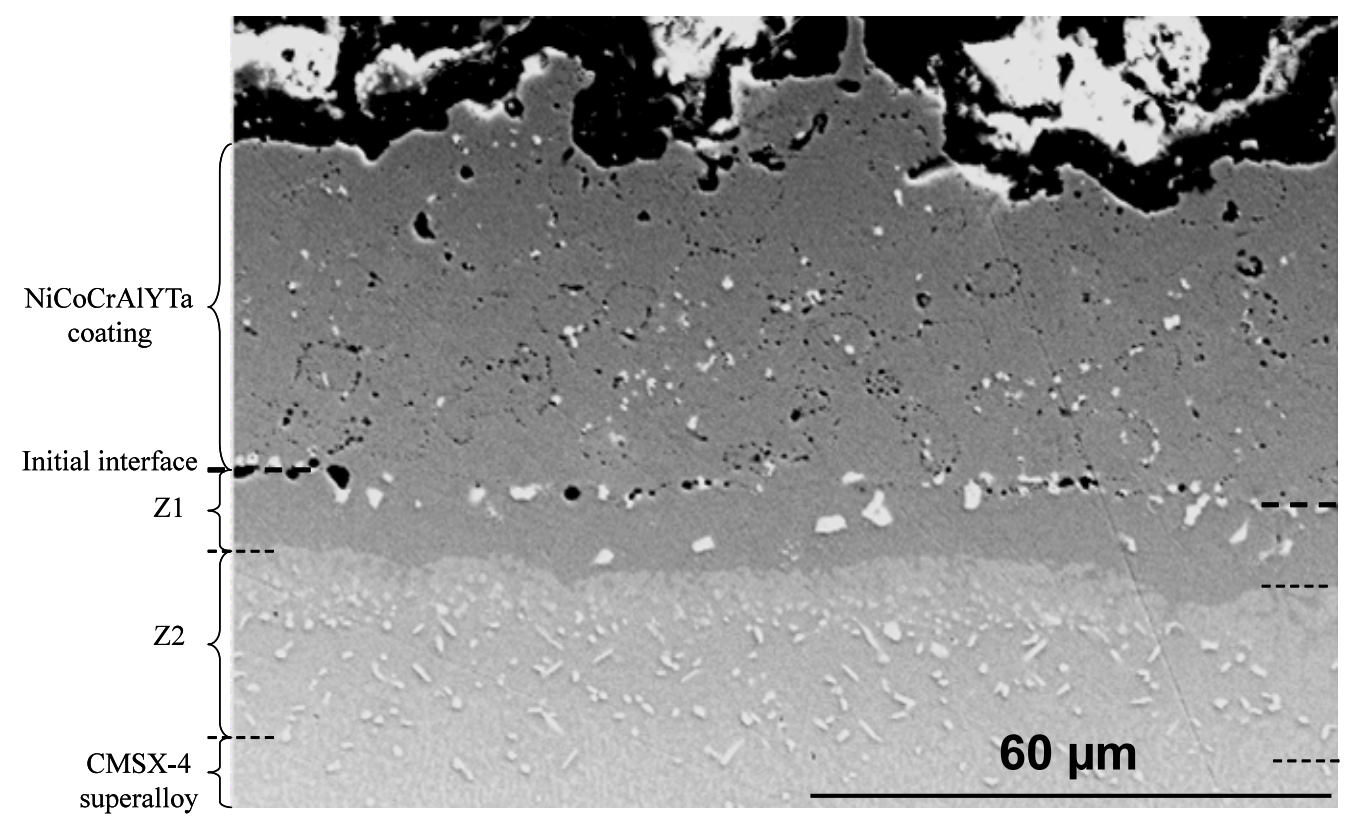

b)

Figure 4. NiCoCrAlYTa coating and interdiffusion with CMSX-4 substrate after creep test rupture at $1050^{\circ} \mathrm{C}$ and $140 \mathrm{MPa}$. a) isothermal creep test; b) thermal cycling creep test with $1 \mathrm{~h}$ high temperature dwell times

In Figure 4.a) and b) are represented the microstructures of NiCoCrAlYTa/CMSX-4 system after respectively isothermal and thermal cycling creep tests at $1050^{\circ} \mathrm{C}$. For both these tests, present phases are similar. The position of the original coating/substrate interface is revealed by occasional alumina inclusions (see Figure 4.a)) that result from the original grit blasting of the substrate prior to the application of the NiCoCrAlYTa coating Interdiffusion between the coating and substrate resulted in the formation of two distinct zones in the CMSX-4 superalloy. The first one (Z1 in Figure 4.b)) just below the initial interface is a $\gamma$ (plus residual $\beta$ at $1150^{\circ} \mathrm{C}-140 \mathrm{MPa}$ ) growth zone in which some tantalum- and titanium-rich precipitates formed. 
Table III. Microstructure observations of coating/substrate interdiffusion zones (Z1 and Z2) after isothermal and thermal cycling creep tests at $1050^{\circ} \mathrm{C}-140 \mathrm{MPa}, 1150^{\circ} \mathrm{C}-140 \mathrm{MPa}$ and $1150^{\circ} \mathrm{C}-80 \mathrm{MPa}$. $\mathrm{Z}_{\text {tot }}$ : total interdiffusion zone thickness, $\mathrm{t}_{\mathrm{cyc}} / \mathrm{t}_{\text {iso }}$ : lifetime ratios (thermal cycling/isothermal) of observed samples

\begin{tabular}{ccccccc}
\hline & & Quantity of TCP & $\mathrm{Z} 1(\mu \mathrm{m})$ & $\mathrm{Z} 2(\mu \mathrm{m})$ & $\mathrm{Z}_{\text {tot }}(\mu \mathrm{m})$ & $\mathrm{t}_{\text {cyc }} / \mathrm{t}_{\text {iso }}$ \\
\hline \multirow{2}{*}{$1050^{\circ} \mathrm{C}-140 \mathrm{MPa}$} & Isothermal & intermediate & 9 & 15 & 24 & - \\
\cline { 2 - 8 } & Thermal cycling & numerous & 9 & 26 & 35 & 0,79 \\
\hline \multirow{2}{*}{$1150^{\circ} \mathrm{C}-140 \mathrm{MPa}$} & Isothermal & numerous but small & $23(+\beta)$ & 5 & 28 & - \\
\cline { 2 - 8 } & Thermal cycling & numerous but very small & $14(+\beta)$ & 13.5 & 27.5 & 0,78 \\
\hline \multirow{2}{*}{$1150^{\circ} \mathrm{C}-80 \mathrm{MPa}$} & Isothermal & very few & 45.5 & - & 45.5 & - \\
\cline { 2 - 7 } & Thermal cycling & very few & 23 & 20 & 43 & 0,37 \\
\hline
\end{tabular}

Just beneath this $\mathrm{Z} 1$ a second zone can be observed (Z2 in Figure 4.b)). This last zone is mainly composed of $\gamma$ and $\gamma^{\prime}$ phases, with a varying $\gamma^{\prime}$ amount. The $\gamma^{\prime}$ domains are always much coarser than in the base superalloy and in some cases a $\gamma^{\prime}$ layer can be observed (without any $\gamma$ phase), such layer generally includes topologically close packed (TCP) precipitates. For all the samples tested in this study at $1050^{\circ} \mathrm{C}$ and $1150^{\circ} \mathrm{C}$ similar observations could be drawn except for the isothermal creep test at $1150^{\circ} \mathrm{C}$ $80 \mathrm{MPa}$ for which $\mathrm{Z2}$ thickness was nil. The differences among these tests concern principally the thicknesses of the different subcoating zones and the quantity of TCP phases. These differences are listed in the Table III.

On the hand, if we consider the column of $\mathrm{Z} 1$ associated with the lifetime ratios $t_{\text {cyc }} / t_{\text {iso }}$ between thermal cycling and isothermal tests for each condition, one can notice that the thickness of this layer is reasonably well correlated to the square root of the high temperature exposure time, in agreement with a diffusion phenomenon. Thermal cycling does not seem to affect the growth

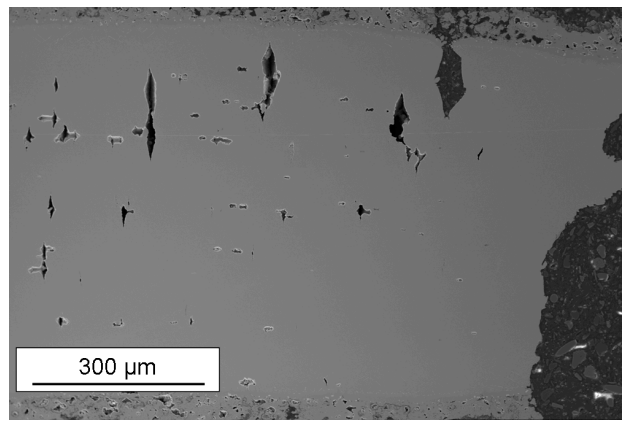

a)

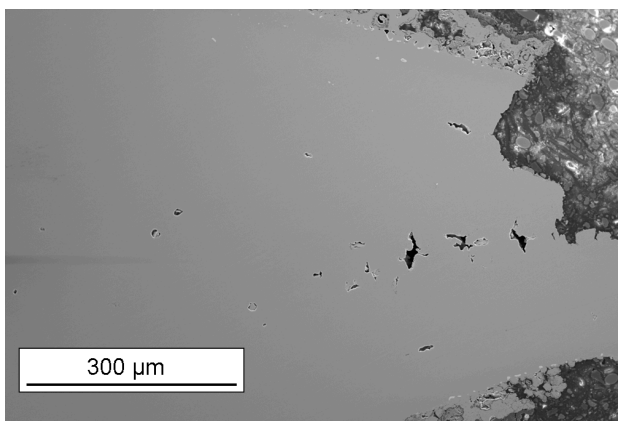

c) of this zone. On the other hand, for the three conditions the Z2 thickness of thermal cycling sample is much higher than the one of isothermal sample. Thus it seems that the growth of this late layer, which corresponds to the formation of TCP particles, is significantly affected by the thermal cycling during creep test. At $1050^{\circ} \mathrm{C}$ and $140 \mathrm{MPa}$ these TCP particles are quite numerous but not very elongated for both tests. They are also numerous at $1150^{\circ} \mathrm{C}-140 \mathrm{MPa}$ but very small whereas they are very rare at $1150^{\circ} \mathrm{C}$ and $80 \mathrm{MPa}$. The density of TCP particles is similar between isothermal and thermal cycling samples in each condition. Their number is higher in the thermal cycling samples since the $\mathrm{Z} 2$ layer is thicker.

\section{Damage accumulation by creep cavitation}

Comparison of damage accumulation by creep cavitation was performed between isothermal and thermal cycling creep tests.

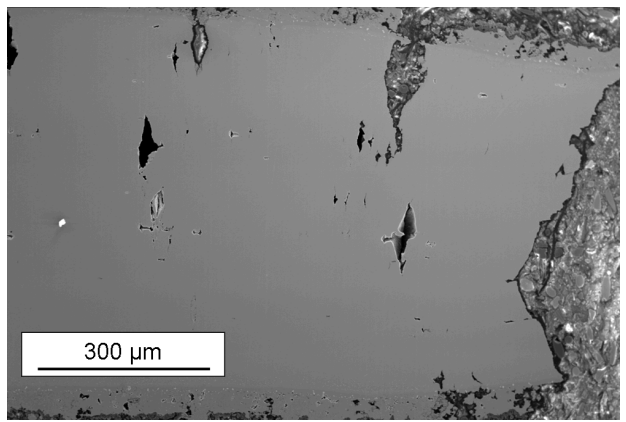

b)

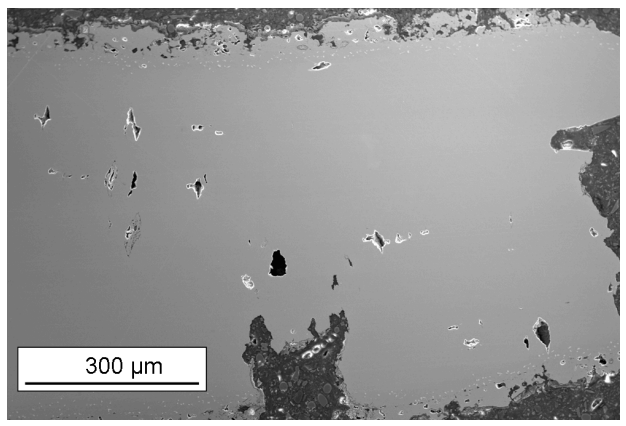

d)

Figure 5. Low magnification SEM micrographs illustrating the formation of creep cavitation in the creep samples at $1050^{\circ} \mathrm{C}-140 \mathrm{MPa}$ (a): isothermal, b): thermal cycling) and $1150^{\circ} \mathrm{C}-80 \mathrm{MPa}(\mathrm{c})$ : isothermal, d): thermal cycling) near the rupture surfaces. Horizontal direction is parallel to tensile axis and rupture surfaces are at right of micrographs. 
Despite the different mechanical behaviors that were evidenced for the different creep conditions, damage, in the form of porosity, was only observed in a limited length of the specimen, very closed from the rupture surface. The results are illustrated in Figure 5 that shows the vicinity of the rupture surfaces for the conditions $1050^{\circ} \mathrm{C}-140 \mathrm{MPa}$ (a): isothermal and b): thermal cycling) and $1150^{\circ} \mathrm{C}-80 \mathrm{MPa}$ (c): isothermal and d): thermal cycling). Observations in the whole gauge lengths were also performed but are not presented here. These observations reveal very few differences between isothermal and thermal cycling creep samples. One can firstly notice that the cavitation is associated particularly with the well-aligned casting pores. Moreover the final fracture is highly localized in all the cases (isothermal and thermal cycling) and illustrated by the tearing of pores perpendicular to the tensile axis. These pores are quite numerous in the vicinity of the rupture surfaces but their number decreases very rapidly away from this zone. The pores are more numerous at $1050^{\circ} \mathrm{C}-140 \mathrm{MPa}$ than at $1150^{\circ} \mathrm{C}-80 \mathrm{MPa}$ and they are practically non-existent at $1150^{\circ} \mathrm{C}-140 \mathrm{MPa}$.

\section{Discussion}

The results presented in this paper reinforce the finding that imposing a thermal cycling during a creep experiment alters the creep resistance of $\gamma / \gamma^{\prime}$ single crystal superalloys $[5,6,9,13]$. In previous studies it have been demonstrated that this detrimental effect only occurred for creep tests performed at very high temperatures, namely for MC2 superalloy thermal cycling had nearly no effect for high temperature level up to $950^{\circ} \mathrm{C}$ [29]. This is to be correlated with the partial dissolution of $\gamma^{\prime}$ precipitates, which in the case of MC2 and CMSX-4 alloys occurs in the temperature range of $950^{\circ} \mathrm{C}-1250^{\circ} \mathrm{C}$. The tests achieved on CMSX-4 superalloy at $1050^{\circ} \mathrm{C}$ and $1150^{\circ} \mathrm{C}$ in this study confirm these conclusion. However the effect of thermal cycling on creep behavior is more or less pronounced depending on the tested conditions. Indeed the decrease of the lifetime is much more severe at $1150^{\circ} \mathrm{C}$ and $80 \mathrm{MPa}$ than for both other conditions. These results confirm after previous studies $[5,13]$ the importance of two thermal cycle parameters, as well as the high temperature level: the high temperature dwell duration during the thermal cycle and the number of thermal cycles. In fact, during an isothermal creep test performed at $1150^{\circ} \mathrm{C}$ the $\gamma^{\prime}$ volume fraction may drop down to $45 \%$ [22] as compared to the initial $70 \%$. Any low temperature incursion may thus lead to the re-precipitation of $\gamma$ ' particles, often reported as "secondary" precipitates [5,22,30]. During the thermal cycle, this re-precipitation is necessarily followed by some dissolution upon heating again at $1150^{\circ} \mathrm{C}$ as shown by the quantitative analysis of $\gamma^{\prime}$ precipitates along the thermal cycle [12,29]. Such re-precipitation - dissolution sequences, by affecting the superalloy microstructure accelerates both creep rate and the destabilization of the rafted morphology as supported by the present results at $1150^{\circ} \mathrm{C}$ and $80 \mathrm{MPa}$.

The condition at $1050^{\circ} \mathrm{C}$ and $140 \mathrm{MPa}$ is less affected by thermal cycling than the one at $1150^{\circ} \mathrm{C}$ and $80 \mathrm{MPa}$ in terms of creep lifetime and rafted morphology destabilization. It results from the fact that the high temperature dwell time is longer (one hour as compared to five minutes at $1150^{\circ} \mathrm{C}$ and $140 \mathrm{MPa}$ ) that implies more spaced in time re-precipitation - dissolution sequences, as well as an overall smaller number of cycles. Moreover setting the high temperature level to $1050^{\circ} \mathrm{C}$ limits the $\gamma^{\prime}$ dissolution. The $\gamma^{\prime}$ volume fraction was measured in the literature to be about 55$60 \%$ at $1050^{\circ} \mathrm{C}$ [22]. The less important gap of $\gamma^{\prime}$ volume fraction between low and high temperature levels and the smaller number of re-precipitation - dissolution sequences result in a less pronounced destabilization of the rafted morphology and thus a less severe effect of thermal cycling on creep. No effect of thermal cycling on $\gamma / \gamma^{\prime}$ topological inversion has been evidenced for this condition since the topological inversion has been observed for both isothermal and thermal cycling test samples. The destabilization of the rafted microstructure through a topological inversion of the $\gamma / \gamma^{\prime}$ microstructure during the creep life has been explicitly reported for CMSX-4 at $950^{\circ} \mathrm{C}$ [31] and $1100^{\circ} \mathrm{C}[31,32]$. The $\gamma / \gamma$ ' topological inversion owes to the growing activity of dislocations in both $\gamma$ and $\gamma^{\prime}$ phases and induces an increase of the creep rate [24].

At $1150^{\circ} \mathrm{C}$ and $140 \mathrm{MPa}$ the condition is too severe to evidence a strong effect of thermal cycling on creep behavior. In fact the lifetime is too short with or without thermal cycles (only few hours) because of the very high stress imposed at this temperature. Nevertheless after the tests at the three conditions the damaging effect of the thermal cycling has been clearly evidenced and it appears that the modifications of the creep behavior and damage processes could be principally related to the $\gamma^{\prime}$ re-precipitation and dissolution sequences during thermal changes.

However the role of thermal cycling on the interdiffusion zone between NiCoCrAlYTa coating and CMSX-4 superalloy should be probably considered, more particularly because of the thin walled geometry of sample studied here even though according to Hüttner et al. [18] noticeable short creep lifetimes of thin coated specimens can be explained only partly by the reduction of the load-bearing cross-section. Indeed although the thermal cycles do not change the present phases and the interdiffusion zone morphology, it seems that thermal cycling has to result to grow more rapidly the subcoating layer where $\gamma$ ' phase is predominant and TCP particles form. This could promote a deeper destabilization of the rafted microstructure in the substrate below the coating. Moreover, although data about the influence of TCP phases on the mechanical properties of superalloys are quite limited and somewhat contradictory, according to notably Epishin et al. [33] precipitation of the TCP phases reduces the creep lifetime of CMSX-4. Even though the TCP phase precipitation is not very large in the observed samples, the accelerated and accentuated growth of this layer during thermal cycling tests could have some detrimental effects on the creep behavior of thinwalled pieces of CMSX-4.

According to notably Reed et al. [22] the TCP particles act as sites for the nucleation pores. Two forms of porosity are then observed: casting porosity, which is predominantly in the interdendritic regions, and porosity in association with the TCP particles, which will have formed via the condensation of vacancies. It has been claimed that creep life should be controlled by the growth of this latter porosity, associated to the precipitation of the TCP phases. However very few differences between isothermal and thermal cycling creep samples have been evidenced in terms of quantity and form of pores, both in the bulk superalloy and in the vicinity of rupture surface. In both tests the two forms of porosity are observed and casting pores outnumber significantly the TCP pores, the quantity of TCP pores does not seem to be larger in thermal cycling creep sample. Thus the results of tests performed in the present study seem to indicate that thermal cycling could favor TCP phase precipitation, at least in the subcoating zone.

However, in bulk of non-isothermal creep sample, thermal cycling does not seem to have particularly favored the formation of TCP pores. 


\section{Conclusions}

The main conclusions that can be drawn from this study are:

1. For the three conditions tested $\left(1050^{\circ} \mathrm{C}-140 \mathrm{MPa}, 1150^{\circ} \mathrm{C}-80\right.$ $\mathrm{MPa}$ and $1150^{\circ} \mathrm{C}-140 \mathrm{MPa}$ ) thermal cycling is detrimental to both creep strain rate and creep lifetime of the coated CMSX-4 superalloy.

2. A higher thermal cycling frequency increases minimum creep strain rate and reduces creep lifetime due to re-precipitation dissolution sequences in quick succession what induces acceleration of rafted microstructure destabilization.

3. Thermal cycling seems to affect deeper the interdiffusion zone in the substrate by promoting the more rapid growth of the subcoating layer where $\gamma^{\prime}$ phase is predominant and TCP particles form.

4. This effect of thermal cycling on TCP growth does not seem to be correlated to an extended number of porosity and to the associated damaging process.

\section{Acknowledgements}

This work is supported by Turbomeca - SAFRAN group. The authors wish to acknowledge Dr Jonathan Cormier, from P' Institute, Poitiers, France, for his help with image analysis and stimulating discussions.

\section{References}

1. T.M. Pollock, and A.S. Argon, "Creep resistance of CMSX-3 nickel-base superalloy single-crystals," Acta Metallurgica et Materialia, 40 (1) (1992), 1-30.

2. V. Sass, U. Glatzel, and M. Feller-Kniepmeier, "Creep anisotropy in the monocrystalline nickel-base superalloy CMSX4", Superalloys 1996, ed. R.Kissinger et al., (Warrendale, PA: TMS, 1996), 283-290.

3. T. Link et al., "Increase of misfit during creep of superalloys and its correlation with deformation," Acta Materialia, 48 (8) (2000) 1981-1994.

4. G. Eggeler, and A. Dlouhy, "On the formation of $\langle 010\rangle$ dislocations in the $\gamma^{\prime}$-phase of superalloy single crystals during high temperature low stress creep," Acta Materialia, 45 (10) (1997) 4251-4262.

5. A. Raffaitin et al., "The effect of thermal cycling on the high temperature creep behaviour of a single crystal nickel-based superalloy," Scripta Materialia, 57 (2007), 277-280.

6. J. Cormier, X. Milhet, and J. Mendez, "Non-isothermal creep at very high temperature of the nickel-based single crystal superalloy MC2,” Acta Materialia, 55 (2007) 6250-6259.

7. F. Touratier et al., "Rafting microstructure during creep of the MC2 nickel-based superalloy at very high temperature," Materials Science and Engineering A, 510-511 (2009) 244-249.

8. J. Cormier, and G. Cailletaud, "Constitutive modeling of the creep behavior of single crystal superalloys under non-isothermal conditions inducing phase transformations," Materials Science and Engineering A, 527 (2010) 6300-6312.
9. J. Cormier et al., "Non-isothermal creep behavior of a second generation Ni-Based single crystal superalloy: experimental characterization and modeling," Superalloys 2008, ed. R.C. Reed et al. (Warrendale, PA: TMS, 2008), 941-949.

10. M. Hantcherli et al., "Evolution of interfacial dislocation network during anisothermal high-temperature creep of a nickelbased superalloy," Scripta Materialia, 66 (2012) 143-146.

12. B. Viguier, F. Touratier, and E. Andrieu, "High-temperature creep of single-crystal nickel-based superalloy: microstructural changes and effects of thermal cycling," Philosophical Magazine, 91 (35) (2011) 4427-4446.

13. R. Goti, B. Viguier, and F. Crabos, "Thermal cycling creep behaviour of single crystal nickel-based superalloy" (Paper presented at the $12^{\text {th }}$ International Conference on Creep and Fracture of Engineering Materials Structures, Kyoto, Japan, May 27-31, 2012)

14. B. Viguier et al., "Microstructure evolution and deformation mechanisms during thermal cyclic creep of a single crystal nickel based superalloy" (Paper presented at the $16^{\text {th }}$ International Conference on Strength of Materials, Bangalore, India, August, 2012).

15. M.J. Pomeroy, "Coatings for gas turbine materials and long term stability issues," Materials and Design, 26 (2005) 223-231.

16. P.J. Henderson, and L. Lindé, "Creep of coated and uncoated thin-section CMSX-4", Materials for Advanced Power Engineering (Forschungszentrum Juelich GmbH, 1998), 15591568

17. M. Doner, and J.A. Heckler, "Identification of mechanisms responsible for degradation in thin-wall stress rupture properties," Superalloys 1988, ed. S. Reichman et al. (Warrendale, PA: TMS, 1988), 653-662.

18. R. Hüttner et al., "First creep results on thin-walled singlecrystal superalloys," Materials Science and Engineering A, 510511 (2009) 307-311

19. K. Harris et al., "Development of the Rhenium containing for single crystal blade and directionally superalloys CMSX-4® \& CM 186 LC® solidified vane applications in advanced turbine engines," Superalloys 1992, ed. S.D. Antolovich et al. (Warrendale, PA: TMS, 1992), 297-306.

20. T. Taylor, and J. Foster, "Thermal expansion of Tribomet MCrAlY coatings," Surface \& Coatings Technology, 201 (7) (2006), 3819-3823.

21. R. Mevrel, and R. Morbioli, "MCrAlY coatings" (Paper presented at the First International Congress "High-TechnMaterials and Finishing”, Berlin, Germany, March 12-14, 1989).

22. R.C. Reed, D.C. Cox, and C.M.F. Rae, "Damage accumulation during creep deformation of a single crystal superalloy at $1150^{\circ} \mathrm{C}, "$ Materials Science and Engineering A, 448 (2007) 88-96 
23. A. Fredholm, and J.-L. Strudel, "High temperature creep mechanisms in single crystals of some high performance nickel base superalloys," High temperature Alloys, their Exploitable Potential, Proceedings of the Petten International Conference, ed. J.B. Mariott et al. (London, U.K.: Elsevier Applied science, 1987), 9-18.

24. P. Caron, C. Ramusat, and F. Diologent, "Influence of the $\gamma$ ' fraction on the $\gamma / \gamma$ ' topological inversion during high temperature creep of single crystal superalloys," Superalloys 2008, ed. R.C. Reed et al. (Warrendale, PA: TMS, 2008), 159-167.

25. M. Coster, and J.-L. Chermant, Précis d'analyse d'images (Paris, France: Presses du CNRS, 1989), 23.

26. R. Mevrel, and C. Duret, "Interdiffusion effects between protective coatings on superalloy substrates" (Paper presented at Advanced Workshop: Coatings for Heat Engines, Aquafredda di Maretea, Italy, April 1-6, 1984)

27. P. Mazars, D. Manesse, and C. Lopvet, "Interdiffusion of MCrAlY coating with the substrate," High temperature alloys for gas turbines and other applications 1986, ed W. Betz et al. (D. Reidel Publishing Company, Dordrecht, Holland, 1986), 11831192.

28. A. Raffaitin et al., "Advanced burner-rig test for oxidationcorrosion resistance evaluation of MCrAlY/superalloys systems," Surface \& Coatings Technology, 201 (2006) 3829-3835.

29. F. Touratier, "Etude des mécanismes de déformation et d'endommagement du superalliage à base de nickel MC2 en fluage aux très hautes temperatures" (Ph.D. thesis, Institut National Polytechnique, Université de Toulouse, France, 2008), 70-75.

30. J.-B. Le Graverend et al., "Effect of fine $\gamma$ ' precipitation on non-isothermal creep and creep-fatigue behaviour of nickel base superalloy MC2", Materials Science and Engineering A, 527 (2010) 5295-5302.

31. H. Mughrabi, " $\gamma / \gamma$ ' rafting and its effect on the creep and fatigue behaviour of monocrystalline superalloys," The Johannes Weertman Symposium, ed. R.J. Arsenault et al. (Warrendale, PA: TMS, 1996), 267-278.

32. A. Epishin, and T. Link, "Mechanisms of high-temperature creep of nickel-based superalloys under low applied stresses," Philosophical Magazine, 84 (19) (2004), 1979-2000.

33. A. Epishin et al., "Creep damage of single-crystal nickel base superalloys: mechanisms and effect on low cycle fatigue," Materials at high temperatures, 27 (1) (2010) 53-59. 